\title{
Clinical Unit
}

National Cancer Institute

\section{Source}

National Cancer Institute. Clinical Unit. NCI Thesaurus. Code C48482.

The amount of a substance required to achieve a specified, measurable physiological change in a controlled environment. 